\section{Divulgação Científica em Astronomia no Observatório Abrahão de Moraes}

\section{Scientific Dissemination of Astronomy at the Observatory Abrahão de Moraes}

\section{RESUMO}

O Observatório Abrahão de Moraes, com sede no município de Valinhos-SP e acesso por Vinhedo-SP, é um laboratório de pesquisa científica pertencente ao Instituto de Astronomia, Geofísica e Ciências Atmosféricas da Universidade de São Paulo. Graças aos interesses e esforços de professores, alunos e funcionários, ele gradativamente abriu suas portas à divulgação científica, sendo hoje, reconhecidamente, um importante centro de difusão do conhecimento na região, atingindo também cidades mais distantes. Esta difusão se dá através de contatos diretos com o público nas visitações diurnas, bastante frequentes, nas noites de observações regulares, ambas com agendamento prévio e ainda nos eventos esporádicos como Portas abertas e Férias com mais estrelas, além de palestras e estágios. Além disso, tem também um contato indireto bastante intenso, através do uso de um de seus telescópios via internet e de frequentes inserções na mídia, principalmente regional. Desde 2008 são recebidos, em média, mais de 2000 visitantes por ano e pode ser muito mais ainda, desde que tenha infraestrutura material e humana adequadas. $\mathrm{O}$ aprimoramento das condições atuais está no horizonte da instituição, vindo de encontro à valorização, cada vez maior, que a USP e outros órgãos financiadores de pesquisa estão dando a essas atividades.

Palavras-chave: Divulgação Científica. Observação do Céu. Observatório.

\section{ABSTRACT}

The Abrahão de Moraes Observatory, established in the city of Valinhos-SP, and accessed by Vinhedo-SP, is a laboratory of scientific research belonging to the Institute of Astronomy, Geophysics and Atmospheric Sciences of the University of São Paulo. Due to the interests and efforts of professors, students and staff, it gradually opened its doors to scientific dissemination and now is recognized as an important center for dissemination of knowledge in its region, reaching even other farther cities. This

\section{RAMACHRISNA \\ TEIXEIRA, \\ Ana Cecília Soja, \\ LuCiene da Silva \\ COELHO, \\ Rafael Miloni \\ SANTUCCI E \\ Elisa Carolina \\ Arizono}

Universidade de São Paulo. Instituto de Astronomia, Geofísica e Ciências Atmosféricas, São Paulo, Brasil 
diffusion occurs in direct contact through the quite frequently daytime visitations and nights of regular observations, both with prior reservation and even with sporadic events like open doors days, lectures and scholarships. Moreover, the indirect contact with public is also very intense through the use of one of its telescopes via Internet and recurrent insertions in the media, especially regional. Since 2008 , are received, on average, more than 2,00o visitors each year, a number that may increase with adequate human and physical infrastructure. The improvement of the current conditions is on the horizon of the institution, encountering the increasing appreciation, which the University and other research funding agencies have been attributing to these activities.

Keywords: Scientific Dissemination. Sky Observation. Observatory.

\section{INTRODUÇÃO}

O Observatório Abrahão de Moraes (OAM) do Instituto de Astronomia, Geofísica e Ciências Atmosféricas da Universidade de São Paulo (IAG-USP), situado no Município de Valinhos-SP, com acesso por Vinhedo-SP, nasceu de um esforço inicial em meados dos anos 60 que visava instalar uma estação de Tempo-Latitude em São Paulo. Este esforço foi liderado e ampliado pelo Prof. Dr. Abrahão de Moraes, o qual contou com a colaboração essencial dos doutores Jean Delhaye, do Observatório de Paris, Alexander Postoiev, do Observatório de Pulkovo (São Petersburgo, Rússia, na época trabalhando no IAG), Pierre Grudler do Observatório de Besançon e Paulo Benevides Soares, na época doutorando no Observatório de Besançon.

Após alguns anos de pesquisa intensa de sítio, a equipe concluiu que o melhor local para a instalação do Observatório seria a região de Viracopos, entre Campinas e São Paulo. Fatores geológicos, topográficos e proteção vegetal levaram o Observatório para o Morro dos Macacos no município de Valinhos-SP, com altitude de $730 \mathrm{~m}$. Esse terreno foi desmembrado da fazenda do Senhor Manoel de Sá Fortes Junqueira e doado à Universidade de São Paulo pela Prefeitura Municipal de Valinhos, com escritura outorgada pelo então Prefeito, Luiz Bissoto, em 3 de Junho de 1971 [1].

Terminada a construção, por decisão do Conselho Universitário da USP, o Observatório recebeu o nome de seu idealizador, falecido em 2 de dezembro de 1970, passando a chamar-se Observatório Abrahão de Moraes. Foi inaugurado em 19 de Abril de 1972 pelo então governador do Estado de São Paulo, Laudo Natel, e pelo reitor da USP, doutor Miguel Reale. Essa cerimônia contou com a presença de muitas autoridades, entre elas o Prefeito de Valinhos, Luiz Bissoto, e os professores doutores Paulo Benevides Soares e Luiz Bernardo Ferreira Clauzet.

Em seu início, o Observatório recebeu dois instrumentos astrométricos: o Telescópio Círculo Meridiano Askania Zeiss e o Astrolábio Impessoal de Danjon, cujas observações destinavam-se à materialização de sistemas de referência, ao estudo da rotação da Terra e movimento do polo. Pouco depois, o Observatório recebeu um terceiro instrumento astronômico, um telescópio Boller \& Chivens de $60 \mathrm{~cm}$, visando coletar dados para pesquisa em Astrofísica. No início dos anos 80 seus horizontes 
foram novamente ampliados com a instalação da estação sismográfica, que faz parte da Rede Sismográfica do Brasil. No final da mesma década, em colaboração com uma equipe alemã, a aceleração da gravidade foi determinada de forma absoluta em um ponto específico do Observatório e desde então tem sido utilizada como referência na calibração de gravímetros e estudos de maré terrestre. Também foi construído um marco geodésico absoluto, utilizado para estudos de Geodésia.

Mais tarde, início dos anos 90, o Observatório vivenciou uma diminuição de suas atividades científicas com a transferência de seu principal instrumento, o telescópio de $60 \mathrm{~cm}$, para o Observatório do Pico dos Dias, em Brazópolis-MG. Esta mudança foi causada pelo crescimento das cidades na região onde se encontra o Observatório e consequente aumento da poluição luminosa. Um pouco depois, outro de seus instrumentos (Astrolábio Impessoal de Danjon) foi transferido para São Paulo, para ser automatizado, e hoje encontra-se desativado. Da origem, o instrumento que ficou, o Círculo Meridiano (Figura 1 e Figura 2), foi automatizado em 1995 com a instalação de um detector eletrônico de luz, construído em colaboração com o Observatório de Bordeaux (França), e até hoje produz observações de boa qualidade e exploráveis cientificamente.

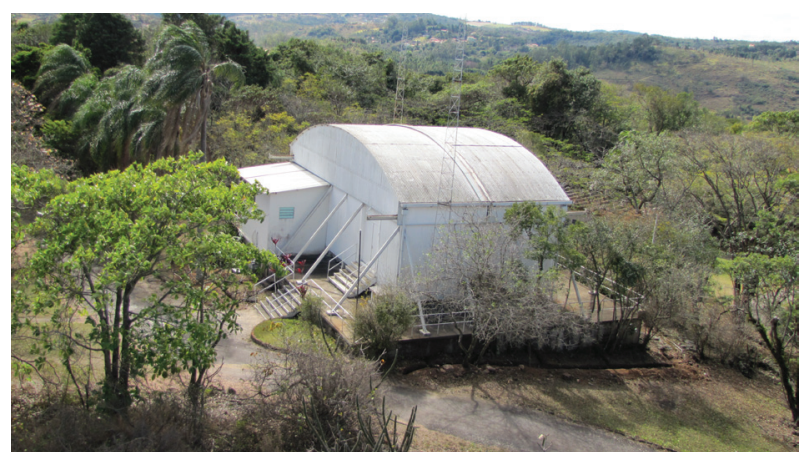

Figura 1 - Vista da área da cúpula do Telescópio Círculo Meridiano. Fonte: Acervo do OAM.

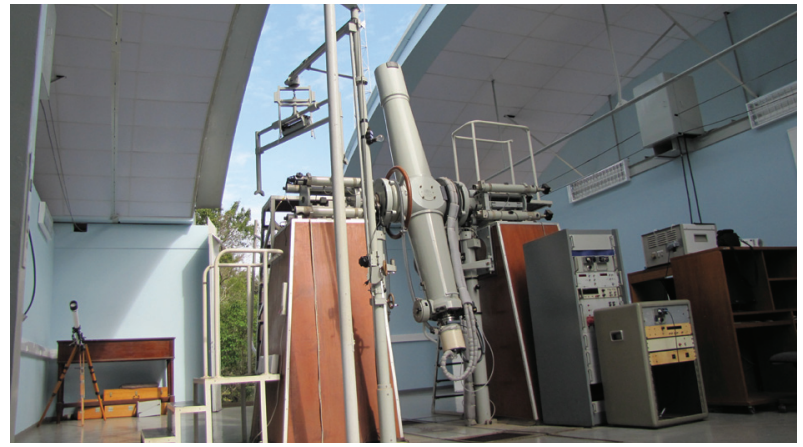

Figura 2 - Telescópio Círculo Meridiano com o detector eletrônico de luz acoplado. Fonte: Acervo do OAM.

Paralelamente a estas constantes mudanças, o Observatório tornou-se um importante centro de difusão do conhecimento na região, através de uma interação direta com o público em eventos esporádicos como o Portas Abertas e outros eventos frequentes, por exemplo, visitas diurnas previamente agendadas e visitas regulares como 
o Noite com as Estrelas. Também existe uma interação indireta importante com a população através do projeto Telescópios na Escola, que está presente na mídia regional. Hoje o Observatório é uma referência importante para o turismo cultural, não só na Região Metropolitana de Campinas, mas também em regiões mais afastadas, incluindo a cidade de São Paulo [2]. Nessas atividades com o público o Observatório conta com a colaboração - que infelizmente oscila muito - das Prefeituras Municipais de Valinhos e de Vinhedo.

O Observatório possui uma área de aproximadamente $450.000 \mathrm{~m}^{2}$, com a maior parte sendo coberta por mata nativa onde se encontram abrigadas e protegidas várias espécies de plantas e animais silvestres. A mata do Observatório é hoje um dos poucos remanescentes florestais na região que ainda são preservados. Ela atua como refúgio vital para diversos animais como macacos (Figura 3), veados, lobos, variados tipos de pássaros (Figura 4) e mais de 150 espécies de borboletas repertoriadas. Desde 1998 é cadastrado no IBAMA como área de soltura de animais silvestres.

Figura 3 - Sagui-de-Tufos

(Callithrix penicillata), uma das três espécies de primatas

frequentemente encontradas no Observatório. Fonte: Acervo do OAM.

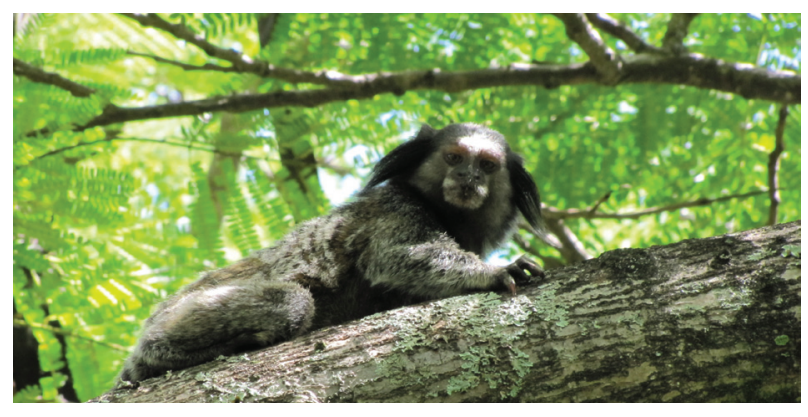

Figura 4 - Gavião Carcará (Polyborus plancus) no Observatório. Fonte: Acervo do OAM.

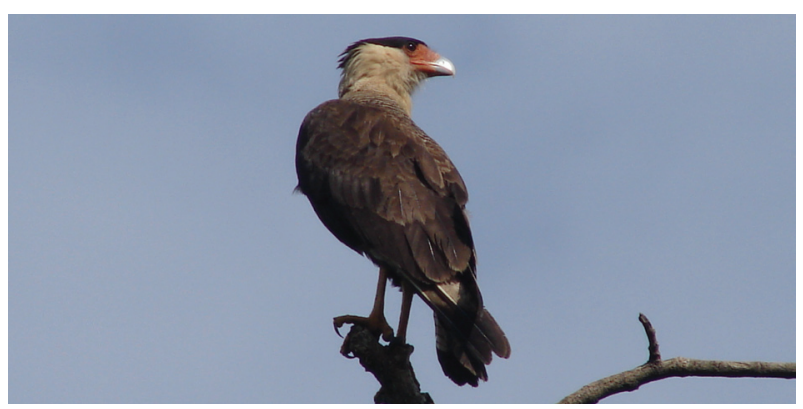

Atualmente, em consequência da expansão de suas atividades, o OAM está recebendo um aporte material importantíssimo e, em breve, estará dotado de melhor infraestrutura para acolher seus visitantes, cumprindo, assim, seu papel na produção e difusão do conhecimento científico como idealizado por seus fundadores.

\section{DIFUSÃO DO CONHECIMENTO NO OBSERVATÓRIO}

Desde sua origem, o Observatório sempre atraiu a atenção da população regional, que 
no início raramente podia acessá-lo. As dificuldades em receber visitas na época eram muitas: não existia pessoal capacitado para tal no local, as visitas noturnas atrapalhavam os trabalhos observacionais com finalidade científica e, devido às características dos telescópios e equipamentos a eles acoplados, não era possível mostrar imagens de corpos celestes (interessantes para o público não especializado) como o público em geral quer ver. É também verdade que, nesta época, a Universidade e a própria sociedade brasileira ainda não davam tanta importância quanto hoje ao trabalho de divulgação científica.

Mesmo assim alguns poucos professores, por tendência natural, se dispuseram a receber visitas e a mostrar os instrumentos ao público. Em 1995, com a automação do Círculo Meridiano, foi possível acumular um número de imagens que proporcionam um espetáculo interessante, motivador e muito apreciado pelo público (Figura 5). Essas imagens são especialmente interessantes, pois são imagens científicas acessíveis ao público leigo, capazes de proporcionar a chance de vislumbrar o céu como o cientista o faz. Junta-se a isso o fato de que, nessa época, foi possível realizar noites de observação com o público utilizando um telescópio MEADE de 12 polegadas, gentilmente emprestado ao Observatório pela Escola Integrando, de Itatiba. Com isso, a procura aumentou e a resposta da instituição foi positiva.

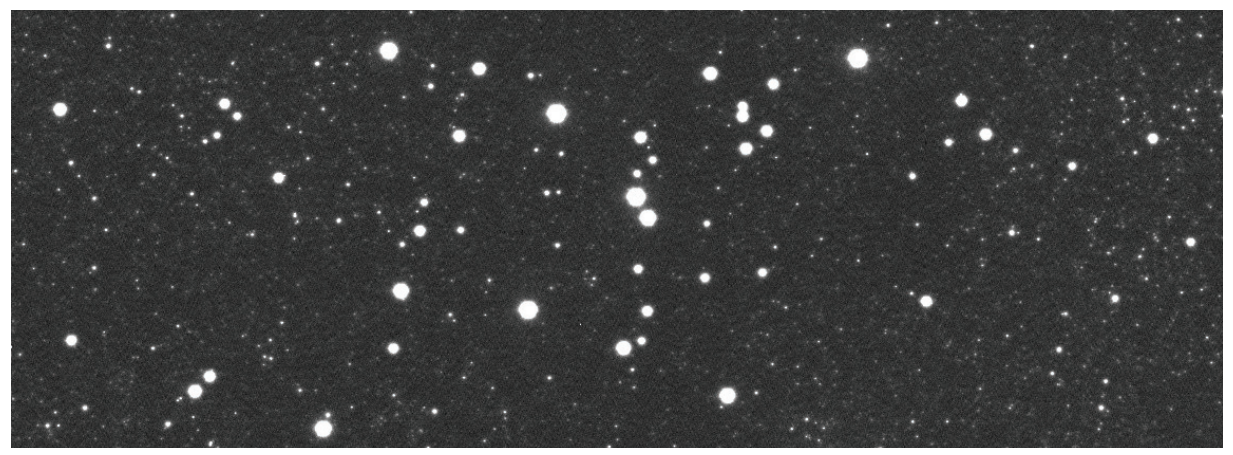

Em 1998, já imersos nessa nova realidade, foi realizado o primeiro evento Portas Abertas, quando o público pode circular livremente pelo Observatório no período das 10 h̀̀ 17 horas, atraindo em torno de 200 visitantes adultos (crianças não foram contabilizadas na época). A repercussão dessa empreitada foi muito grande e serviu de impulso para a ampliação das atividades com o público. Nessa mesma época, ocorreu um estágio para formação de 20 professores do Ensino Fundamental e Médio de escolas da região. Também data dessa época a visitação cada vez mais intensa por parte dos cursos de extensão universitária do Departamento de Astronomia do próprio IAG e de seus cursos regulares de graduação.

Naturalmente, a procura aumentou ainda mais e desde, aproximadamente, 2007, essas atividades de divulgação se solidificaram com o envolvimento de alunos/monitores, permitindo manter certa regularidade, incluindo visitas noturnas mensais.

Em 2007, alunos de graduação do Instituto de Física da Universidade de São Paulo
Figura 5 - Aglomerado Estelar M6, observado com o Telescópio Círculo Meridiano. Fonte: Acervo do OAM. 
(IF-USP), em sintonia com o Prof. Dr. Ramachrisna Teixeira, do IAG-USP, então responsável pelo Observatório, diante dessa nova realidade, se dispuseram a colaborar sistematicamente com as atividades de divulgação no Observatório, através de observações do céu noturno com telescópios: inicialmente com um telescópio MEADE de 10 polegadas do IAG. Dois anos depois, esses esforços resultaram na compra de dois telescópios MEADE de 12 polegadas, nomeados Prometeu e Asterix, voltados exclusivamente para esse fim. A utilização de dois equipamentos ampliou a capacidade e a própria dinâmica do atendimento, promovendo ainda mais o estreitamento da relação entre o público em geral e o ambiente da Universidade.

\footnotetext{
Figura 6 - Telescópios Prometeu e Asterix, atualmente utilizados no evento Noite com as Estrelas. Fonte: Acervo do OAM.
}

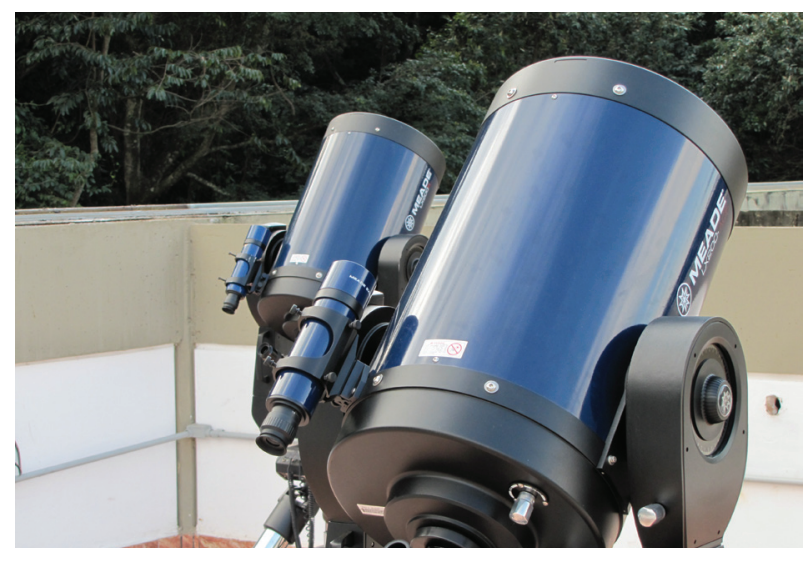

O evento noturno criado para receber o público em geral foi nomeado Noite com as Estrelas, que será descrito a seguir, e é realizado sistemática e periodicamente. Ao mesmo tempo, o Observatório recebe um grande número de visitantes durante o dia. Nestes casos, os visitantes são principalmente turmas escolares de todos os níveis, do pré-primário à pós-graduação.

\section{Noite com as Estrelas}

Até recentemente, as visitas noturnas ocorriam principalmente para os alunos do próprio IAG-USP (apenas uma ou duas turmas por ano). Na realidade, tratava-se de uma extensão das atividades diurnas com estes alunos de Graduação e de Pós-graduação. Esta limitação ocorria principalmente pelo fato do OAM não ter um telescópio voltado para o público, pois os telescópios usados em pesquisa são dotados de câmeras especiais. Além disso, a presença do público no Observatório durante a noite impediria que ali se desenvolvessem atividades normais de pesquisa. Outra importante limitação vinha do fato de que o Observatório não dispunha de funcionários e nem de infraestrutura adequada para esta finalidade

Desde 2007, com os telescópios Prometeu e Asterix adquiridos com auxílio do $\mathrm{CNPq}$, e com a disposição das várias gerações de alunos/monitores, desenvolveu-se o evento mensal Noite com as Estrelas. Este evento ocorre às sextas, sábados e domingos 
de Lua crescente. Para a realização desta atividade, contou-se em algum momento com a ajuda financeira da Pró-Reitoria de Cultura e Extensão Universitária da USP, do CNPq, das Prefeituras de Valinhos e de Vinhedo e claro, do próprio IAG.

No evento Noite com as Estrelas os visitantes são recebidos na sala de palestras, em grupos de no máximo 35 pessoas (três grupos por noite no inverno e dois no verão), para uma rápida apresentação do Observatório (10 a 15 minutos) e, em seguida, são encaminhados para a cúpula onde então passarão em torno de uma hora observando o céu (Lua, planetas, aglomerados, nebulosas, galáxias e estrelas), a maioria pela primeira vez. Este momento também é aproveitado para verdadeiras e descontraídas aulas do céu a olho nu, reconhecimento de algumas estrelas, constelações, movimento aparente dos astros, diferenças entre planetas e estrelas, entre outros assuntos relacionados à Astronomia. Nestas noites de observação é fundamental o auxílio de funcionários do Observatório. Este evento é realizado na fase crescente da Lua, pois a Lua é um dos objetos mais espetaculares para o público e neste caso, encontra-se acima do horizonte na primeira metade da noite, certamente mais conveniente, mesmo para crianças.

Naturalmente, essa atividade foi estendida a muitas turmas de graduação do IAG-USP compreendendo sempre a visitação diurna e observações noturnas.

No Noite com as Estrelas, em caso de mau tempo (céu encoberto) a atividade programada é substituída por uma palestra, filme e/ou uma visita aos instrumentos do Observatório.

Neste momento já está em funcionamento a primeira de duas plataformas de observação. Estas plataformas estão sendo construídas de forma a permitir que as observações sejam realizadas no nível do solo, facilitando assim o acesso de todos, sobretudo daqueles com mobilidade reduzida. A segunda plataforma será construída em breve no mesmo ambiente da primeira. Além de facilitar o acesso, estas plataformas possibilitam o atendimento simultâneo de um número maior de pessoas.

O evento é inteiramente gratuito e atualmente é mantido com oito alunos/monitores, seis bolsistas de graduação e dois de pós-graduação. Estas bolsas são fornecidas pela Pró-Reitoria de Cultura e Extensão Universitária e são essenciais na manutenção dessa atividade. Além deles, conta-se sempre com a presença de pelo menos um funcionário e/ou o Professor Coordenador.

O Noite com as Estrelas é divulgado em redes sociais e no site do Observatório (www.observatorio.iag.usp.br), dentre outras formas de divulgação eletrônica, e também nos meios de comunicação regionais, como estações de rádio e jornais. A divulgação atual é cada vez mais expressiva e já atende não apenas às cidades de Valinhos e Vinhedo, mas a toda a região metropolitana de Campinas e também a cidade de São Paulo e suas cidades satélites.

\section{Visitação Diurna}

As visitas diurnas duram aproximadamente 60 a 90 minutos e acontecem com agendamento prévio. No caso de escolas e grupos organizados, o agendamento se dá segundo a conveniência de ambas as partes. Os visitantes avulsos são agrupados e, desde que seja 
constituído um grupo razoável de pessoas (aproximadamente 30), agenda-se a visita com a devida antecedência. Em geral essas visitas ocorrem aos sábados pela manhã.

$\mathrm{O}$ atendimento, na maioria das vezes, tem sido realizado pelo professor coordenador e pelo técnico de laboratório do Observatório, auxiliados por outros funcionários do OAM. Devido às limitações material e humana, essas visitações têm estado muito aquém de responder à demanda e também aquém das potencialidades do Observatório.

A visita diurna consiste em uma conversa informal de mais ou menos 20 minutos com o grupo no auditório do Observatório, onde os visitantes são recebidos: fala-se de Astronomia, do que se faz em um observatório e do que se faz mais especificamente no OAM. A seguir, o grupo é levado para conhecer cada um dos telescópios, sendo que no Círculo Meridiano, devido às dimensões do pavilhão onde se encontra, são projetadas algumas imagens do céu coletadas com o instrumento. Em nossa avaliação, mostrar as imagens ainda que projetadas, coletadas com o instrumento que as pessoas estão visitando, tem se revelado muito mais interessante e atraente do que mostrá-las em uma sala de aula ou auditório. Dependendo do grupo e do tempo gasto na visita, e também das condições de céu, são feitas observações do Sol com o telescópio solar (Telescópio Coronado de 40mm de abertura e distância focal de 40omm), concebido e construído com essa finalidade.

As maiores limitações no caso das visitas diurnas são consequência da pouca disponibilidade do professor responsável pelo Observatório e do técnico de laboratório. Mesmo assim, em vários sábados são realizadas visitas diurnas, grupos de visitantes avulsos e excursões didáticas, incluindo aqueles no período do evento Noite com as Estrelas quando estão presentes também os alunos/monitores. Estas limitações também impedem a exploração com o público, de fenômenos ocasionais como eclipses, cometas, chuvas de meteoros, entre outros.

\section{Portas Abertas e Férias com Mais Estrelas}

Até o momento, foram realizados quatro eventos do tipo Portas Abertas, onde o público é convidado a visitar o Observatório durante o dia, sem que seja necessário qualquer tipo de agendamento. O primeiro foi realizado em 1998, recebendo aproximadamente 200 adultos, número considerado bem sucedido. $\mathrm{O}$ segundo evento desse tipo foi realizado em 2012, como parte das comemorações dos 40 anos do Observatório. Nele estiveram presentes pouco mais de 1000 adultos, evidenciando a crescente busca por esse tipo de atividades na região, bem como a bem sucedida divulgação.

O terceiro evento, realizado em julho de 2014 sob o título Férias com Mais Estrelas recebeu em torno de 850 visitantes e consistiu novamente na abertura do Observatório, agora por uma semana e com mais atividades, como palestras e oficinas. Graças ao sucesso dessa primeira edição, ficou consolidada a realização de eventos temáticos anuais e sua segunda versão foi realizada em julho de 2015 atraindo novamente em torno de 1000 visitantes.

Esse tipo de evento atrai muita gente e dá muita visibilidade para o Observatório. Entretanto, sua organização não é simples e necessita da colaboração e envolvimento de um número muito maior de pessoas: funcionários, alunos e professores, o que 
nem sempre ocorre com a intensidade desejada.

Nos eventos de 2012, 2014 e 2015, o público teve à sua disposição um grande número de atrativos e atividades: músicas, exposições, atividades interativas para crianças, observações do Sol, estrelas, planetas e Lua. O resultado foi excelente e espera-se repetir e ampliar este evento em muitas ocasiões futuras. Com a realização desses eventos, também ficou evidente o quanto a demanda na região por eventos culturais é grande e o quanto o Observatório Abrahão de Moraes ainda está longe de atendê-la. Entretanto, o OAM certamente é capaz de supri-la, pois ainda possui enorme potencial.

\section{TELESCÓPIOS NA ESCOLA (TNE)}

O projeto Telescópios na Escola consiste em observações remotas, via internet, tanto de roteiros didáticos quanto no modo livre. O Observatório disponibiliza para as escolas um telescópio Celestron, chamado Argus (Figura 7), de 11 polegadas, que opera de forma totalmente automática, permitindo aos alunos realizarem observações a partir da própria escola. Pela internet o professor é capaz de acessar e mover o telescópio para o objeto astronômico desejado e "fotografá-lo" conforme a atividade a ser realizada. O TnE abrange escolas de várias regiões do Estado de São Paulo e também de outros estados que o utilizam com regularidade.

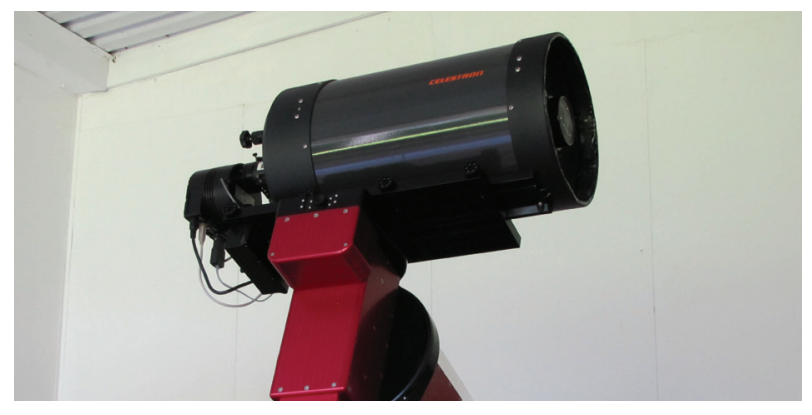

Figura 7 - Telescópio Argus, utilizado no projeto Telescópios na Escola. Fonte: Acervo do OAM.

As observações são previamente agendadas e, nas noites e horários estabelecidos, o telescópio, localizado no OAM, fica à disposição da escola que irá comandá-lo remotamente, de qualquer lugar, via internet, apontando-o para os objetos desejados e coletando as imagens em tempo real, como se estivesse no local.

Esse projeto é mais amplo e consiste em uma rede de sete telescópios automáticos instalados em várias cidades do país. O projeto foi inicialmente financiado pela Fundação Vitae, sob a coordenação do Prof. Dr. Laerte Sodré, do IAG. Hoje, sob a coordenação da Profa. Dra. Vera Jatenco, duas outras atividades estão sendo incorporadas a esta envolvendo as estações sismográfica e meteorológica do OAM, denominadas Geofísica na Escola e Meteorologia na Escola, respectivamente.

Esse projeto foi implantado em 2005 e tem contado com bolsistas de graduação da Pró-Reitoria de Cultura e Extensão Universitária da USP. Seu alcance pode ser facilmente ampliado se o Observatório puder contar com recursos humanos voltados para o 
trabalho de divulgação científica, disponibilizando mais noites de observação às escolas.

\section{ESTATÍSTICA DO ATENDIMENTO AO PÚBLICO NO OBSERVATÓRIO}

No gráfico a seguir pode-se perceber o aumento e o patamar em que se encontra a visitação pública ao Observatório Abrahão de Moraes. O Gráfico 1 deixa claro que a partir de 2008 se instalou em definitivo um novo quadro no que diz respeito à visitação ao Observatório. As oscilações estão principalmente ligadas ao mau tempo nos dias do Noite com as Estrelas e também à disponibilidade de recursos humanos para a realização dos eventos e consequentemente maior investimento na sua divulgação.

Gráfico 1 - Número de visitantes por ano, contabilizados até 27 de agosto de 2015.

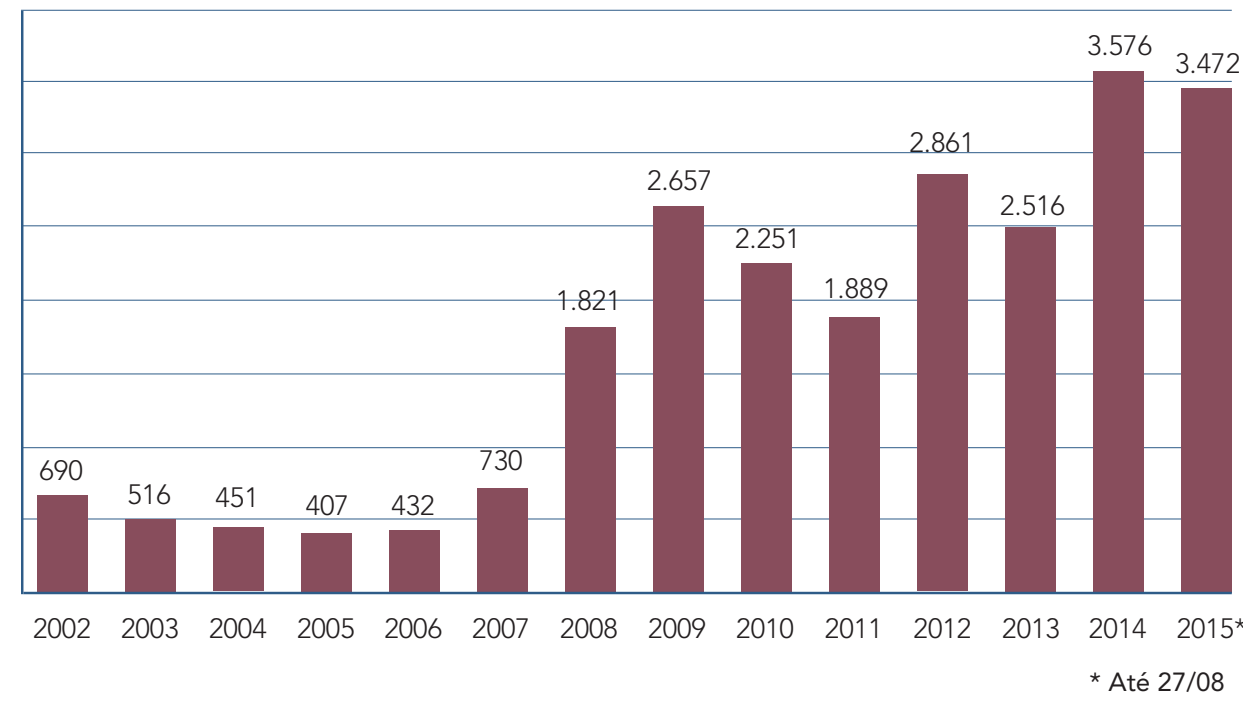

Já no Gráfico 2, podemos ver como estão distribuídos os visitantes. Nesta figura, o item "Graduação" corresponde apenas aos alunos do IAG que nos visitam nas chamadas Excursões Didáticas, lideradas pelos professores. Naturalmente, este número pode aumentar muito caso estas excursões se estendam aos demais departamentos do IAG e a toda a Universidade. Da mesma forma, o número de alunos de pós-graduação pode aumentar muito com a divulgação das atividades junto a toda comunidade uspiana. Esse gráfico refere-se somente ao ano de 2015, mas o quadro é aproximadamente o mesmo nos anos anteriores. 
Gráfico 2 - Distribuição dos visitantes por categorias, considerando somente o ano de 2015 (até 27 de agosto).

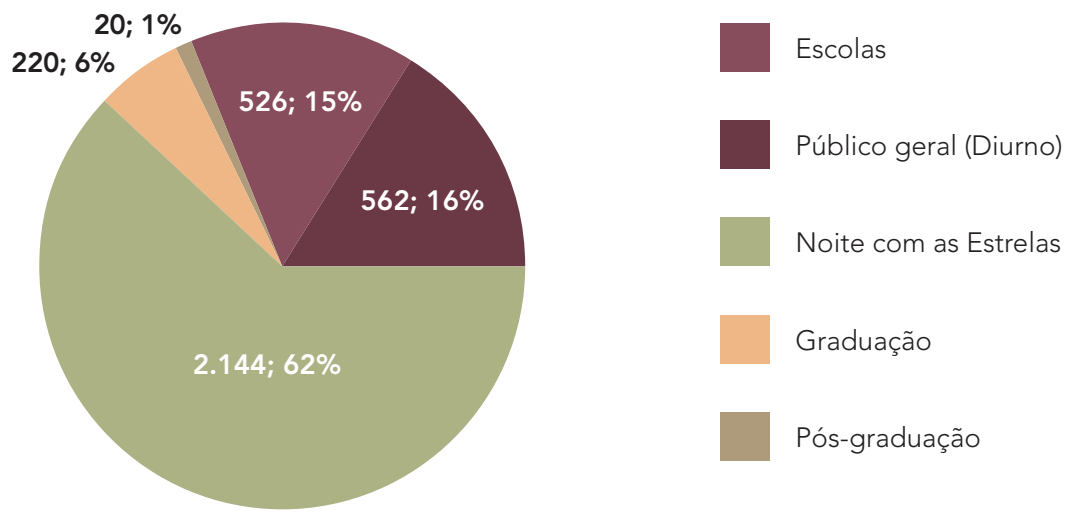

A forma como o público é recebido no OAM foi aprimorada nesses vários anos de atividades e as mudanças tiveram como base dois pontos muito importantes: a vivência dos estudantes que realizam o trabalho e a constatação de que o público visitante possui diferentes níveis de instrução, mas que é predominantemente composto por pessoas com segundo e/ou terceiro graus completos.

No Gráfico 3, a seguir, percebe-se que a grande maioria do público é procedente da região onde se encontra o Observatório, mas há uma parcela significativa oriunda da capital. Estes dados colocam o Observatório como uma importante fonte de divulgação do conhecimento na região. Caracteristicamente, essa região encontra-se entre dois importantes polos de pesquisa (a Universidade de São Paulo e a Universidade Estadual de Campinas), mas possui poucos centros científicos e culturais resultando, portanto, em uma demanda altíssima deste tipo de ambiente. Posicionado em um local estratégico para este fim, o OAM acaba facilitando o acesso e consequente contato, do público leigo com um centro de pesquisa.

Gráfico 3 - Origem dos visitantes do OAM em 2015 (até 27 de agosto).

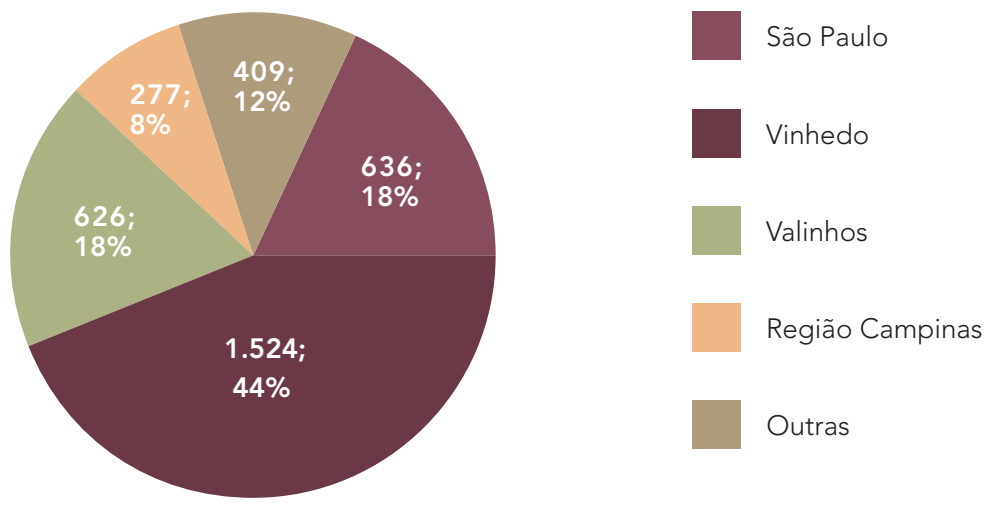




\section{CONSIDERAÇÕES FINAIS E PERSPECTIVAS}

Tanto os adultos quanto as crianças não conseguem esconder a alegria, o prazer e a satisfação com a visita e com o que viram e ouviram. Em geral, a interação é excelente. Desta forma, o Observatório vem cumprindo com sucesso a importante tarefa institucional de divulgação científica, altamente motivadora e fundamental na atração de crianças e jovens para o conhecimento científico. É evidente que a quantidade e a qualidade das atividades de difusão do conhecimento no Observatório Abrahão de Moraes podem ser ampliadas e melhoradas. O Observatório encontra-se em uma região privilegiada e, considerando o nível médio de escolaridade do público visitante, a demanda é muito maior do que aquela que é oferecida com a infraestrutura e apoio disponíveis hoje. Com as devidas ampliações, as atividades realizadas no Observatório serão ainda mais um grande incentivo para crianças e jovens a seguirem carreiras na pesquisa científica. Também, com a melhoria destas condições, seria possível aumentar a divulgação de todas as atividades, inclusive científicas, e desenvolver mais eventos públicos e realizar atividades mais focadas, como, por exemplo, a formação de professores. Certamente existe muito espaço para crescer.

Outro ponto que merece destaque é a contribuição fundamental que a realização dessas atividades dá à formação dos alunos/monitores, que em sua grande maioria se tornarão professores e pesquisadores.

Apesar da aceleração do desenvolvimento científico do país nos últimos anos, tomando como referência os principais centros de pesquisa do mundo, vê-se que ainda há muito o que fazer e crescer. Certamente, uma das atividades mais importantes neste processo é a divulgação científica que, se bem feita, muito além de informar, atrai e motiva o público em geral para o conhecimento, principalmente o público mais jovem. A Astronomia, por um lado, é por excelência uma área extremamente atraente e motivadora. O Observatório Abrahão de Moraes encontra-se em uma região com enorme demanda educacional, cultural e mesmo turística. A Universidade de São Paulo é uma das maiores instituições de ensino e pesquisa do país (a melhor colocada em rankings internacionais), todos estes ingredientes apontam um retorno, difícil de medir, mas garantido, que é a aproximação entre a academia e a população, que tem sido cada vez mais valorizado.

\section{REFERÊNCIAS}

[1] MARQUES DOS SANTOS, P. Instituto Astronômico e Geofísico da USP: Memória sobre sua formação e evolução. $1^{\text {a }}$ ed. São Paulo: Editora Universidade de São Paulo, 2005. 
[2] TOMANIK, G. B.; CAVENAGHI, A.J. Lazer e turismo: Visitas ao Observatório Abrahão de Moraes/IAG-USP (SP, Brasil). Revista Brasileira de Pesquisa em Turismo, v. 6, n. 3, pp. 375-397, 2012.

\section{AGRADECIMENTOS}

Os autores são gratos a todos aqueles que, direta ou indiretamente, têm contribuído para o desenvolvimento das atividades de divulgação científica no Observatório Abrahão de Moraes. Em especial, agradecemos aos Prof. Dr. Laerte Sodré, atual Diretor do IAG, e Profa. Dra. Vera Jatenco, responsáveis pelo TNE. Também destacamos o excelente trabalho desenvolvido por todos os monitores da graduação, bolsistas e voluntários, que têm passado pelo Observatório nos últimos anos. Igualmente importante tem sido a participação dos funcionários lotados no Observatório e os funcionários da administração do IAG. E finalmente, somos gratos ao CNPq, à Pró-Reitoria de Cultura e Extensão Universitária, ao IAG e às Prefeituras Municipais de Valinhos e Vinhedo pelo suporte financeiro, material e logístico.

RAMACHRISNA TEIXeIRA professor do Departamento de Astronomia do Instituto de Astronomia, Geofísica e Ciências Atmosféricas da Universidade de São Paulo (IAG-USP) e-mail: rama.teixeira@iag.usp.br

ANA CECÍlIA SOJA doutoranda do Departamento de Astronomia do Instituto de Astronomia, Geofísica e Ciências Atmosféricas da Universidade de São Paulo (IAG-USP) - e-mail: acsoja@usp.br

LUCIENe DA SILVA coelho doutoranda do Departamento de Astronomia do Instituto de Astronomia, Geofísica e Ciências Atmosféricas da Universidade de São Paulo (IAG-USP) - e-mail: luciene.coelho@usp.br

RAFAel MILONI SANTUCCI doutoranda do Departamento de Astronomia do Instituto de Astronomia, Geofísica e Ciências Atmosféricas da Universidade de São Paulo (IAG-USP) - e-mail: rafaelsantucci@usp.br

ELISA CAROLINA ARIZONO mestranda profissional em Ensino de Astronomia do Departamento de Astronomia do Instituto de Astronomia, Geofísica e Ciências Atmosféricas da Universidade de São Paulo (IAG-USP) - e-mail: arizono@usp.br 